\title{
Preliminary Evaluation of Paecilomyces lilacinus HY-4 to Control Tetrany- chus urticae
}

\author{
Tae-Young Shin ${ }^{1}$, Won-Woo Lee ${ }^{1}$, Seung-Hyun $\mathrm{Ko}^{1}$, Zhen $\mathrm{Ji}^{2}$, Dong-Ha Shin ${ }^{2}$, Kwang-Hee Son ${ }^{3}$, \\ Ho-Yong Park ${ }^{2}$, and Soo-Dong Woo,* \\ ${ }^{I}$ Department of Agricultural Biology, College of Agriculture, Life \& Environment Science, Chungbuk National University, \\ Cheongju 361-763, Korea \\ ${ }^{2}$ Industrial Bio-materials Research Center, Korea Research Institute of Bioscience and Biotechnology (KRIBB), Daejeon $305-$ \\ 806, Korea \\ ${ }^{3}$ Insect Biotech Co. Ltd., Daejeon 305-811, Korea
}

(Received 07 February 2011; Accepted 05 March 2011)

The virulence against the two-spotted spider mite, Tetranychus urticae Koch, was evaluated with entomopathogenic fungus Paecilomyces lilacinus (Thom) Samson HY-4 which is isolated from coleopteran insect and registered to Korean and US patents. Virulence tests were conducted with conidial suspensions (1.5 $\times 10^{6}$ conidia/ml) of $P$. lilacinus HY-4 against $T$. urticae adults and positive results were recorded in laboratory conditions. The spraying device was also developed for the efficient and exact evaluation of treatment. The developed spraying device was named as SD-tower sprayer and its efficacy of spraying conidia was evaluated. The accumulated mortality caused by $P$. lilacinus HY-4 using SD-tower spray was about $73 \%$ at 6 days after inoculation. This suggest that the isolate $P$. lilacinus HY-4 may be considered as promising for a new approach to prevent adult infestations by $T$. urticae.

Key words: Tetranychus urticae, Paecilomyces lilacinus, Entomopathogenic fungi, Tower spray

\section{Introduction}

The two-spotted spider mite, Tetranychus urticae Koch

*To whom the correspondence addressed

Department of Agricultural Biology, College of Agriculture, Life \& Environment Science, Chungbuk National University, Cheongju 361-763, Korea.

Tel: +82-043-261-2553; Fax: +82-043-271-4414;

E-mail: sdwoo@cbnu.ac.kr
(Acari: Tetranychidae) has been recorded on more than 150 hosts of some economic value throughout the world (Irigaray et al., 2003). It is probably the most important pest species in the family Tetranychidae. This pest has become a serious problem because of the large scale use of the chemical insecticides. One explanation for this is that insecticides reduce natural enemies, causing a reduction in predation pressure, which may allow the two-spotted spider mite numbers to increase (Gatarayiha et al., 2010). Chemical acaricides have since been relied upon. However, these are not always effective and their continuous use has resulted in resistance among two-spotted spider mite populations. Like other mites, this pest is capable of rapidly developing extensive resistance to many acaricides (Dagli and Tunc, 2001; Nauen et al., 2001). Thus, there is a need to find alternative control methods to suppress two-spotted spider mites populations.

Entomopathogenic fungi can play an important role in the regulation of arthropod pest populations. Several fungal species have been isolated from their respective hosts and used as pest control agents in many countries (Wraight et al., 1998; Ansari et al., 2004; Vu et al., 2007; Patricia et al., 2008). Recently, some fungi such as Beauveria bassiana (Bals.) Vuill, Metarhizium anisopliae (Metsch.) Sorokin, Hirsutella thompsonii Fisher and Lecanicillium lecanii (Zimm.) (Viegas) Zare \& Gams have been screened against two-spotted spider mite and hold potential for their development as bioacaricides (Tamai et al., 2002a; Chandler et al., 2005; Gatarayiha et al., 2010). In Korea, it is also necessary to develop biological control mechanisms as a part of integrated pest management programs against the two-spotted spider mite. 
Dose-response evaluations of entomopathogenic fungus conducted under controlled conditions typically involve application of known droplet dose onto certain body parts of individual insects and spraying of surfaces with known amounts of fungus (Nansen et al., 2010). Of the two, spraying method is more suitable for small-size insects and practical.

Paecilomyces lilacinus (Thom) Samson HY-4 was isolated from unidentified coleopteran insects in Korea and registered to Korean and US patents with accession number 0035708 and 7435411 , respectively. The present study aimed to evaluate the potential of an entomopathogenic fungus P. lilacinus HY-4 as a candidate for control of twospotted spider mite. For this, novel spraying device is also developed and evaluated its efficacy.

\section{Materials and Methods}

\section{Two-spotted spider mite}

Two-spotted spider mites were obtained from a colony of a continuous culture in the Insect Ecotoxicology Laboratory, Chungbuk National University, Korea. The initial culture originated from two-spider mite collected from Kongju, Korea in 2010. The two-spotted mite population was reared and maintained on garden pea (Pisum sativum L.) at $25^{\circ} \mathrm{C}, 70 \%$ relative humidity, and $12: 12$ (L:D) photoperiod. To obtain fixed-age females for the bioassays, quiescent deutonymphs were collected from the two-spotted spider mite cultures and put on leaf discs. The newly emerged females were used for the experiments 1-2 day later (Wekesa et al., 2005).

\section{Preparation of conidial suspension}

One gram of dry conidia suspended in $10 \mathrm{ml}$ sterile distilled water with $0.05 \%$ Tween- 80 . The conidial suspension was vortexed for 10 min to produce a homogenous suspension. Conidial viability was determined by serial dilution plating onto SDYA, with colony forming unit counted 3 days after incubation at $25^{\circ} \mathrm{C}$ (Glare et al., 2008 ), and results used for adjusting the concentration to $1.5 \times 10^{6}$ viable conidia/ml.

\section{SD- tower sprayer}

To evaluate the virulence of $P$. lilacinus HY-4 against twospotted spider mite, a SD-tower sprayer was constructed by partially modified bottle sprayer method (Nansen et al., 2010). The SD-tower sprayer consists of the following materials: a dual action airbrush (BD-186: Fenghua Bida Machinery Manufacture Co., China) with a $0.3 \mathrm{~mm}$ needle, an acrylic cylinder (diameter: $90 \mathrm{~mm}$, height: $200 \mathrm{~mm}$ ), two of cuboid acrylic supports (area: $4900 \mathrm{~mm}^{2}$, height:

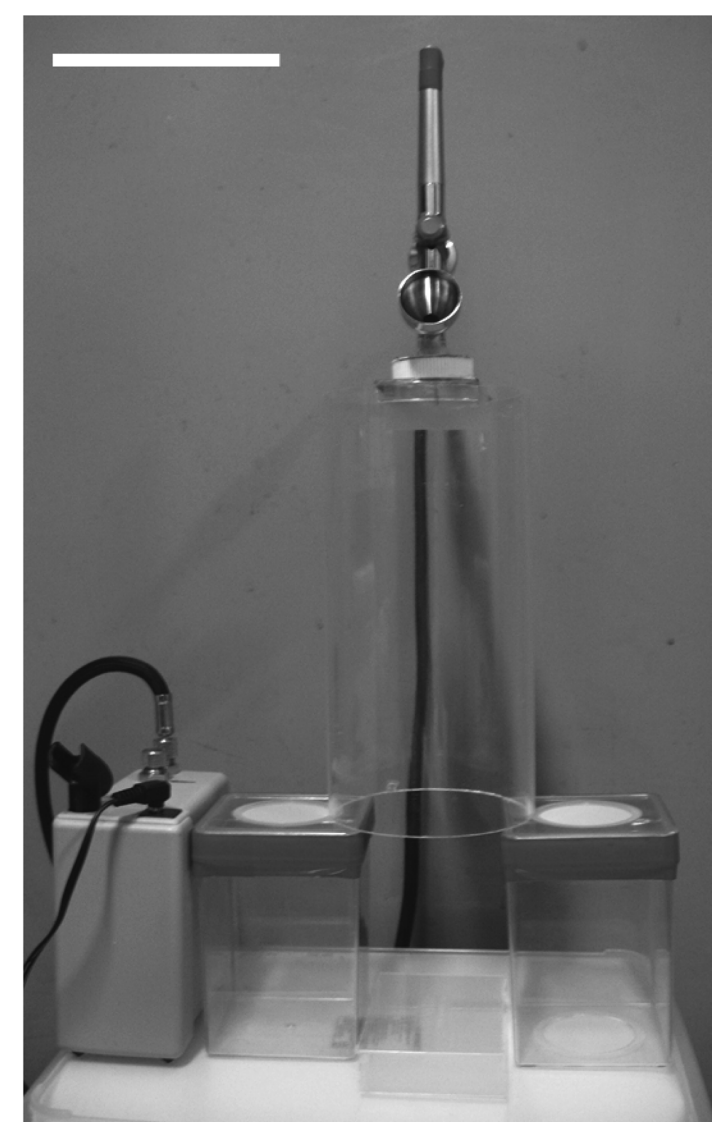

Fig. 1. SD-tower sprayer. Air compressor hose is connected to an airbrush, which is sprayed inside an acrylic cylinder. Scale bars: $100 \mathrm{~mm}$.

$100 \mathrm{~mm}$ ) and air compressor set (working pressure of $1 \mathrm{~kg} / \mathrm{cm}^{2}$ ) (Fig. 1).

\section{Two-spotted spider mite bioassay}

A garden pea without two-spotted spider mites was cut into a $25 \mathrm{~mm}$ diameter circle and placed on moist cotton wool in a $60 \mathrm{~mm}$ petri dish. Fifteen two-spotted spider mite adults were transferred into each dish using a singlehair brush pen. One milliliter of a fungal suspension $\left(1.5 \times 10^{6}\right.$ conidia/ml $)$ was sprayed into a dish using a SDtower sprayer and placed in an incubator at $25^{\circ} \mathrm{C}, 70 \%$ relative humidity, and 12:12 (L:D) photoperiod. Each treatment was repeated 3 times and included control sprayed only with $0.05 \%$ Tween- 80 . Under each of the sprays, a hemocytometer was placed on side of the leaf to collect the deposited conidia. Two-spotted spider mites were checked daily for mortality, and all cadavers were placed at $>90 \%$ relative humidity in an incubator at $25^{\circ} \mathrm{C}$ until conidiation was observed. Cadavers with visible fungal growth on their body surface were considered to have died as a result of fungal infection. 
Table 1. Comparison of deposited conidia between SD-tower sprayer and various potter tower sprayers in bioassays.

\begin{tabular}{ccccc}
\hline Type of tower sprayer & $\begin{array}{c}\text { Amount of applied } \\
\text { conidia }\end{array}$ & Deposited conidia per $\mathrm{cm}^{2}$ & $\begin{array}{c}\text { Rate of Deposited } \\
\text { conidia per } \mathrm{cm}^{2}(\%)\end{array}$ & Reference \\
\hline SD-tower sprayer & $1.5 \times 10^{6}$ conidia & $8.7 \times 10^{3}$ conidia & 0.58 & - \\
Potter tower sprayer & $2 \times 10^{8}$ conidia & $1.49 \times 10^{4}$ conidia & 0.00745 & Shapiro-Ila et al., 2008 \\
& $1 \times 10^{8}$ conidia & $1.2 \times 10^{5}$ conidia & 0.01179 & Shan et al., 2010 \\
& $2 \times 10^{8}$ conidia & $6.9 \times 10^{4}$ conidia & 0.0347 & Shi et al., 2008 \\
& $1 \times 10^{8}$ conidia & $9.7 \times 10^{4}$ conidia & 0.097 & Tian et al., 2006 \\
& $8 \times 10^{6}$ conidia & $1.2 \times 10^{4}$ conidia & 0.15 & Vicentini et al., 2001 \\
\hline
\end{tabular}

\section{Results and Discussion}

\section{Evaluation of SD-tower sprayer}

The mean $( \pm \mathrm{SD})$ concentration of dry conidial P. lilacinus HY-4 deposited onto the leaves was $8.7 \pm 1.4 \times 10^{3}$ conidia $/ \mathrm{cm}^{2}$ for the each sprayed and no detective dead of two-spotted spider mite during one day after inoculation with $0.05 \%$ Tween- 80 . To evaluate efficacy of SD-tower sprayer, we compared the deposited conidia rates with previously reported results using potter tower sprayer in bioassay (Vicentini et al., 2001; Tian et al., 2006; Shapiro-Ila et al., 2008; Shi et al., 2008; Shan et al., 2010;) (Table 1). The result showed that SD-tower sprayer was superior to other sprayers with $0.58 \%$ rate of deposited conidia per $\mathrm{cm}^{2}$. This may be related with the difference of used nozzle of air brush, velocity of air and length of spray tube. Anyway, this suggested that SD-tower sprayer could be used efficiently to bioassay of small-size invertebrate including insects.

\section{Virulence of $P$. lilacinus HY-4 against two-spotted spider mite}

Paecilomyces lilacinus HY-4 caused substantial mortalities of two-spotted spider mite adults on day 6 after spraying compared with those observed in the controls and $73.3 \%$ mortality occurred at 6 days post inoculation (Fig. 2a). Mycosis began to appear on the second day after death (Fig. 2b) and could be seen by naked eye when mite was incubated at high humidity. Generally, $1 \times 10^{8}$ or upper concentration of conidia is used to bioassay, but we achieved high mortality with $1.5 \times 10^{6}$ conidia in this experiment. Therefore, this result suggest that $P$. lilacinus HY-4 may be utilized effectively to control two-spotted spider mite.

Recently, entomopathogenic fungi including B. bassiana, M. anisopliae, P. farinsus (Holmsk) and Hirsutella sp. was considered as promising fungi for two-spotted spider mite control (Tamai et al., 2002a). Paecilomyces lilacinus is a commonly isolated form soil and as one of

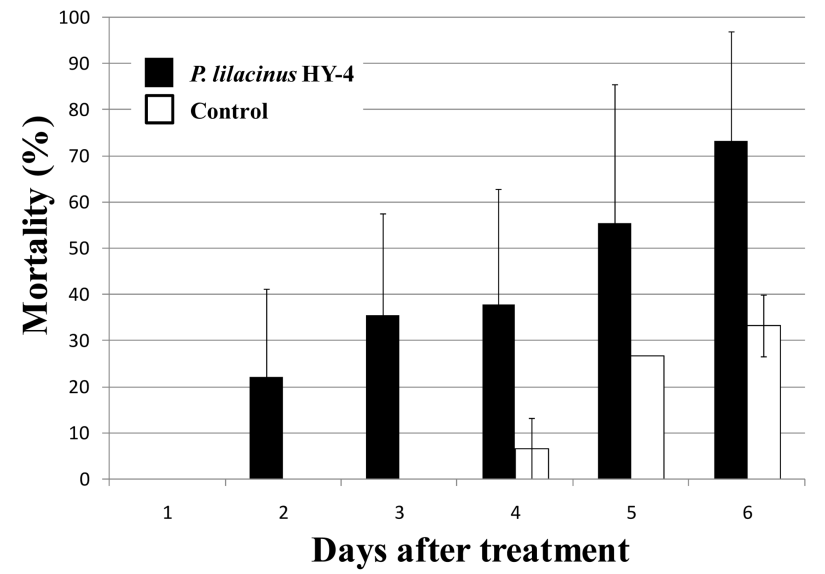

(a)

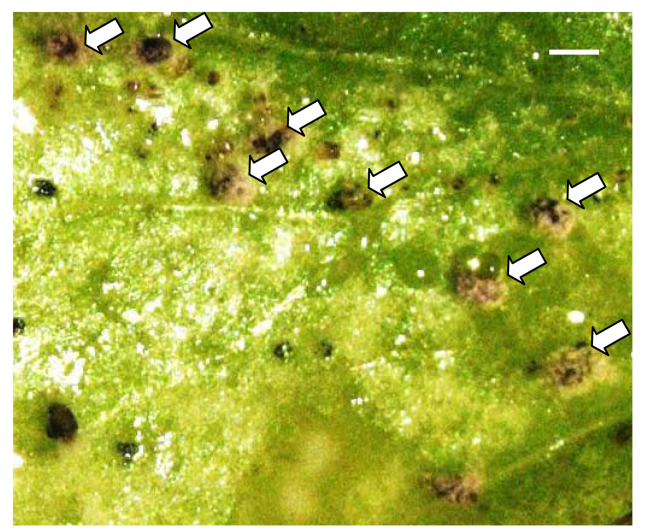

(b)

Fig. 2. (a) The mean $( \pm S D)$ mortality of two-spotted spider mite adults during 6 days after treatment with $4.4 \times 10^{5}$ conidia of $P$. lilacinus HY-4 in $0.05 \%$ Tween- 80 . (b) The two-spotted spider mite adults infected with $P$. lilacinus HY-4 at 2 days after death. Arrows indicate infected mites. Scale bars: (b) $0.5 \mathrm{~mm}$. (Online figure in color).

the effective biological control agents against plant-pathogenic nematodes and pest (Marti et al., 2006; Fiedler and Sosnowska, 2007; Demirci and Denizhan. 2010). Although our isolate $P$. lilacinus HY-4 was isolated from 
coleopteran insect, this study showed that $P$. lilacinus HY4 is also effective pathogen to two-spotted spider mite other than beetles. Although we have not confirmed the efficacy of $P$. lilacinus HY-4 in field condition, we believe that $P$. lilacinus HY-4 have potential for management of two-spotted spider mite.

\section{Acknowledgement}

This work was supported by the grant from the Technology Development Program for Agriculture and Forestry (AGC0911011) of the Ministry for Food, Agriculture, Forestry and Fisheries, Republic of Korea.

\section{References}

Ansari MA, Vestergaard S, Tirry L, Moens M (2004) Selection of a highly virulent fungal isolate, Metarhizium anisopliae CLO 53, for controlling Hoplia philanthus. J Invertebr Pathol 85(2), 89-96.

Chandler D, Davidson G, Jacobson R J (2005) Laboratory and glasshouse evaluation of entomopathogenic fungi against the two-spotted spider mite, Tetranychus urticae (Acari: Tetranychidae), on tomato, Lycopersicon esculentum. Biocontrol Science and Technology 15, 37-54.

Dagli F, Tunc I (2001) Dicofol resistance in Tetranychus cinnabarinus: resistance and stability of resistance in populations from Antalya, Turkey. Pest Manag Sci 57, 609-614.

Demirci F, Denizhan E (2010) Paecilomyces lilacinus, a potential biocontrol agent on apple rust mite Aculus schlechtendali and interactions with some fungicides in vitro. Phytoparasitica 38, 125-132.

Fiedler Z, Sosnowska D (2007) Nematophagous fungus Paecilomyces lilacinus (Thom) Samson is also a biological agent for control of greenhouse insects and mite pests. BioControl 52, 547-558.

Gatarayiha MC, Laing MD, Miller RM (2010) Effects of adjuvant and conidial concentration on the efficacy of Beauveria bassiana for the control of the two spotted spider mite, Tetranychus urticae. Exp Appl Acarol 50, 217-229.

Glare TR, Reay SD, Nelson TL, Moore R (2008) Beauveria caledonica is a naturally occurring pathogen of forest beetles. Mycological Research 112, 352-360.

Irigaray FJS, Mcar-Mancebón V, Pérez-Moreno I (2003) The entomopathogenic fungus Beauveria bassiana and its compatibility with triflumuron: effects on the two spotted spider mite Tetranychus urticae. Biological Control 26, 168-173.

Marti GA, Lastra CC, Pelizza SA, García JJ (2006) Isolation of Paecilomyces lilacinus (Thom) Samson (Ascomycota:
Hypocreales) from the Chagas disease vector, Triatoma infestans Klug (Hemiptera: Reduviidae) in an endemic area in Argentina. Mycopathologia 162(5), 369-372.

Nansen C, Hinson B, Davidson D, Vaughn K, Gharalari AH (2010) Novel Approaches to Application and Performance Assessment of Insecticide Applications to Crop Leaves. J. Econ. Entomol 103(2), 219-227.

Nauen R, Stumpf N, Elbert A, Zebitz CP, Kraus W (2001) Acaricide toxicity and resistance in larvae of different strains of Tetranychus urticae and Panonychus ulmi (Acari: Tetranychidae). Pest Manag Sci 57, 253-61.

Patricia HS, Pedro MOJN, Talita MA, Daniele S, Luis FAA, Maria HPF (2008) Selection of Beauveria bassiana isolates to control Alphitobius diaperinus. J Invertebr Pathol 97(2), 83-90.

Shan LT, and Feng MG (2010) Evaluation of the biocontrol potential of various Metarhizium isolates against green peach aphid Myzus persicae (Homoptera: Aphididae). Pest Manag Sci 66, 669-675.

Shapiro-Ilan DI, Cottrell TE, Jackson MA, Wood BW (2008) Virulence of Hypocreales fungi to pecan aphids (Hemiptera: Aphididae) in the laboratory. J Invertebr Pathol 99(3), 312317.

Shi WB, Feng MG, Liu SS (2008) Sprays of emulsifiable Beauveria bassiana formulation are ovicidal towards Tetranychus urticae (Acari: Tetranychidae) at various regimes of temperature and humidity. Exp Appl Acarol 46, 247-257.

Tamai MA, Alves SB, de Almeida JEM, Faion M (2002a) Evaluation of entomopathogenic fungi for control of Tetranychus urticae Koch (Acari: Tetranychidae). Arq Inst Biol 69, 77-84.

Tian L, Feng MG (2006) Evaluation of the time-concentrationmortality responses of Plutella xylostella larvae to the interaction of Beauveria bassiana with a nereistoxin analogue insecticide. Pest Manag Sci 62, 69-76.

Vicentini S, Faria M, Oliveira MRV (2001) Screening of Beauveria bassiana (Deuteromycotina: Hyphomycetes) isolates against nymphs of Bemisia tabaci (Genn.) biotype B (Hemiptera: Aleyrodidae) with description of a new bioassay method. Neotropical Entomology 30(1), 97-103.

Vu VH, Hong SI, Kim K (2007) Selection of Entomopathogenic Fungi for Aphid Control. J Biosci Bioeng 104(6), 498505.

Wekesa VW, Maniania NK, Knapp M, Boga HI (2005) Pathogenicity of Beauveria bassiana and Metarhizium anisopliae to the tobacco spider mite Tetranychus evansi. Exp Appl Acarol 36(1-2), 41-50.

Wraight SP, Carruthers RI, Bradley CA, Jaronski ST, Lacey LA, Wood P, Galaini-Wraight S (1998) Pathogenicity of the entomopathogenic fungi Paecilomyces spp. and Beauveria bassiana against the silverleaf whitefly, Bemisia argentifolii. J Inverteb. Pathol 71(3), 217-226. 